\title{
Fondaparinux for the Treatment of Superficial-Vein Thrombosis in the Legs
}

\author{
Hervé Decousus, M.D., Paolo Prandoni, M.D., Ph.D., Patrick Mismetti, M.D., Ph.D., \\ Rupert M. Bauersachs, M.D., Zoltán Boda, M.D., Benjamin Brenner, M.D., \\ Silvy Laporte, Ph.D., Lajos Matyas, M.D., Saskia Middeldorp, M.D., Ph.D., \\ German Sokurenko, M.D., and Alain Leizorovicz, M.D., \\ for the CALISTO Study Group*
}

ABSTRACT

From INSERM CIE3, F-42055 (H.D.), EA3065 Université Jean-Monnet (H.D., P.M., S.L.), and Service de Médecine et Thérapeutique (H.D., P.M.) and Unité de Pharmacologie Clinique (P.M., S.L.), Centre Hôpitalier Universitaire Saint-Etienne, Hôpital Nord - all in Saint-Etienne, France; and Unité Mixte de Recherche 5558, Faculté René Thomas Hyacinthe Laennec, Lyon, France (A.L.); the Thromboembolism Unit, University of Padua, Padua, Italy (P.P.); the Department of Vascular Medicine, Medical Department IV, Klinikum Darmstadt, Darmstadt, Germany (R.M.B.); the 2 nd Department of Medicine, University of Debrecen, Debrecen (Z.B.), and the Department of Vascular and Endovascular Surgery, University Teaching Hospital Miskolc, Miskolc (L.M.) — both in Hungary; the Thrombosis and Hemostasis Unit, Rambam Health Care Campus, Technion, Israel Institute of Technology, Haifa, Israel (B.B.); the Departments of Clinical Epidemiology and General Internal Medicine, Leiden University Medical Center, Leiden, the Netherlands (S.M.); and City Hospital 26, St. Petersburg, Russia (G.S.). Address reprint requests to Dr. Decousus at Service de Médecine et Thérapeutique, Hôpital Nord, CHU Saint-Etienne, 42055 Saint-Etienne, CEDEX, France, or at herve .decousus@chu-st-etienne.fr.

*Investigators participating in the Comparison of Arixtra in Lower Limb Superficial Vein Thrombosis with Placebo (CALISTO) trial are listed in the Supplementary Appendix, available at NEJM.org.

N Engl J Med 2010;363:1222-32.

Copyright @ 2010 Massachusetts Medical Society.

\section{BACKGROUND}

The efficacy and safety of anticoagulant treatment for patients with acute, symptomatic superficial-vein thrombosis in the legs, but without concomitant deep-vein thrombosis or symptomatic pulmonary embolism at presentation, have not been established.

\section{METHODS}

In a randomized, double-blind trial, we assigned 3002 patients to receive either fondaparinux, administered subcutaneously at a dose of $2.5 \mathrm{mg}$ once daily, or placebo for 45 days. The primary efficacy outcome was a composite of death from any cause or symptomatic pulmonary embolism, symptomatic deep-vein thrombosis, or symptomatic extension to the saphenofemoral junction or symptomatic recurrence of superficial-vein thrombosis at day 47 . The main safety outcome was major bleeding. The patients were followed until day 77 .

\section{RESULTS}

The primary efficacy outcome occurred in 13 of 1502 patients $(0.9 \%)$ in the fondaparinux group and 88 of 1500 patients (5.9\%) in the placebo group (relative risk reduction with fondaparinux, 85\%; 95\% confidence interval [CI], 74 to $92 ; \mathrm{P}<0.001$ ). The incidence of each component of the primary efficacy outcome was significantly reduced in the fondaparinux group as compared with the placebo group, except for the outcome of death $(0.1 \%$ in both groups). The rate of pulmonary embolism or deep-vein thrombosis was $85 \%$ lower in the fondaparinux group than in the placebo group $(0.2 \%$ vs. $1.3 \%$; $95 \% \mathrm{CI}, 50$ to $95 ; \mathrm{P}<0.001)$. Similar risk reductions were observed at day 77. A total of 88 patients would need to be treated to prevent one instance of pulmonary embolism or deep-vein thrombosis. Major bleeding occurred in one patient in each group. The incidence of serious adverse events was $0.7 \%$ with fondaparinux and $1.1 \%$ with placebo.

\section{CONCLUSIONS}

Fondaparinux at a dose of $2.5 \mathrm{mg}$ once a day for 45 days was effective in the treatment of patients with acute, symptomatic superficial-vein thrombosis of the legs and did not have serious side effects. (Funded by GlaxoSmithKline; ClinicalTrials .gov number, NCT00443053.) 
UPERFICIAL-VEIN THROMBOSIS OF THE legs is a common condition, ${ }^{1,2}$ with an estimated incidence that may exceed that of deep-vein thrombosis., ${ }^{3,4}$ Patients with isolated superficial-vein thrombosis - that is, without concomitant deep-vein thrombosis or symptomatic pulmonary embolism at presentation - are at risk for subsequent symptomatic venous thromboembolic complications. ${ }^{1-7}$ In a large, prospective, observational study, the 3-month risk of such complications was $8.3 \%$, with a $3.3 \%$ risk of deep-vein thrombosis or pulmonary embolism. ${ }^{8}$

The treatment of this disease has not been adequately addressed in randomized trials. Accordingly, the recommendations in various guidelines are weak, and in practice, therapeutic strategies vary, ranging from no treatment to the use of antiinflammatory agents or anticoagulant drugs or surgery. ${ }^{8-14}$ The few randomized studies that have been performed did not clarify the circumstances under which surgery is required or the value or optimal dose and duration of anticoagulant or antiinflammatory therapy. ${ }^{6,15-19}$ The results of the two largest studies, evaluating low-molecular-weight heparin, suggest that high-dose (therapeutic) or intermediate-dose regimens do not provide substantial benefits over low-dose (prophylactic) regimens and that a treatment period of 12 days or of 30 days is too short, with most symptomatic thromboembolic complications occurring after the treatment period. ${ }^{6,17}$ None of the published studies showed a clinically relevant benefit of any treatment as compared with placebo. ${ }^{6,7}$ Thus, the aim of our study was to determine whether there is a well-defined treatment that could provide a benefit.

We conducted the Comparison of Arixtra in Lower Limb Superficial Vein Thrombosis with Placebo (CALISTO) trial to evaluate the efficacy and safety of fondaparinux, a specific factor $\mathrm{Xa}$ inhibitor, in reducing symptomatic venous thromboembolic complications or death from any cause in patients with acute, isolated superficial-vein thrombosis of the legs. For the active treatment, we selected the prophylactic dose of $2.5 \mathrm{mg}$ of fondaparinux once daily, because this dose has been shown to be reasonably effective and to have an acceptable side-effect and adverse-event profile in a broad range of conditions. ${ }^{20-23}$ Treatment was to be administered for 45 days.

\section{METHODS}

\section{PATIENTS}

Hospitalized or nonhospitalized patients 18 years of age or older, with acute, symptomatic lowerlimb superficial-vein thrombosis at least $5 \mathrm{~cm}$ long, as confirmed by standardized compression ultrasonography, were eligible to undergo randomization. Patients were excluded if the interval between the onset of their symptoms and planned randomization was more than 3 weeks; if they had been treated for cancer within the previous 6 months; if they presented with symptomatic or asymptomatic deep-vein thrombosis, symptomatic documented pulmonary embolism, or superficial-vein thrombosis associated with sclerotherapy or placement of an intravenous catheter or located within $3 \mathrm{~cm}$ of the saphenofemoral junction; or if they had a documented history of superficial-vein thrombosis within the previous 3 months or deep-vein thrombosis or pulmonary embolism within the previous 6 months. Patients were also excluded from randomization if they had received an antithrombotic agent for more than 48 hours (other than aspirin at a dose $\leq 325 \mathrm{mg}$ per day) or a nonsteroidal antiinflammatory drug for more than 72 hours as treatment for the current episode of superficial-vein thrombosis or if, in the investigator's opinion, they required ligation of the saphenofemoral junction or stripping of varicose veins. Other exclusion criteria were major surgery within the previous 3 months and conditions that could confer a predisposition to bleeding, including severe hepatic impairment, a creatinine clearance of less than $30 \mathrm{ml}$ per minute, and a platelet count of less than 100,000 per cubic millimeter. Finally, women of childbearing age were excluded if they were pregnant or were not using a reliable contraceptive method.

\section{STUDY DESIGN}

This trial was an international, multicenter, randomized, double-blind, placebo-controlled study; the protocol, including the statistical analysis plan, is available with the full text of this article at NEJM.org. With the use of a central telephone system and a computer-generated randomization list, consecutive patients were randomly assigned, in a 1:1 ratio, to fondaparinux at a dose of $2.5 \mathrm{mg}$ or matching placebo, administered subcutaneously 
once daily for 45 days. Randomization was performed in blocks of four without any stratification. The maximum interval allowed between the qualifying ultrasonographic study and randomization was 48 hours. The day of randomization was defined as day 1 . Follow-up visits were scheduled at days $10 \pm 2,30 \pm 2,45 \pm 2$, and $75 \pm 2$. No routine ultrasonographic examinations were required during the follow-up period. The study was conducted according to the ethical principles stated in the Declaration of Helsinki and local regulations. The protocol was approved by an independent ethics committee, and written informed consent was obtained from all patients before they underwent randomization.

The study was funded by GlaxoSmithKline. A steering committee, including one nonvoting member representing the sponsor, was responsible for the design, conduct, and reporting of the study. Data were collected and analyzed by the study sponsor. The database of adjudicated outcomes was managed by an independent central adjudication committee. The members of the writing committee wrote the first draft of the manuscript and made the decision to submit the manuscript for publication. All the authors contributed to the writing of subsequent drafts of the manuscript, had full access to the data and analyses, and vouch for the accuracy and completeness of the report, as well as the fidelity of the study to the protocol and statistical analysis plan.

\section{STUDY DRUGS}

Fondaparinux and placebo were packaged in identical boxes containing visually identical, prefilled 0.5 -ml single-dose syringes. Each patient received one box containing 45 single-dose syringes ( 1 per day for 45 days) of either $2.5 \mathrm{mg}$ of fondaparinux sodium (Arixtra, GlaxoSmithKline) or placebo (sodium chloride). At the time of randomization, patients were provided with an injection diary. The investigators were encouraged to teach the patients to administer the study drugs themselves, but the final decision about self-administration was left to the investigator's discretion.

Patients were encouraged to use graduated compression stockings and were allowed to take acetaminophen or topical nonsteroidal antiinflammatory drugs as needed. The use of oral antiplatelet agents or aspirin at a low dose $(\leq 325 \mathrm{mg}$ per day) was discouraged. Concomitant treatment with dextran, thrombolytic agents, any other anticoagulant agent, more than one antiplatelet agent, as- pirin at doses higher than $325 \mathrm{mg}$ per day, glycoprotein IIb/IIIa inhibitors, oral nonsteroidal antiinflammatory drugs, or topical heparins or heparinoids was prohibited throughout the course of the study.

\section{OUTCOME MEASURES}

The primary efficacy outcome was the composite of death from any cause, symptomatic pulmonary embolism (confirmed by ventilation-perfusion scanning, helical computed tomography, pulmonary angiography, or autopsy), symptomatic deepvein thrombosis (confirmed by ultrasonography or venography), or symptomatic extension to the saphenofemoral junction or symptomatic recurrence of superficial-vein thrombosis (confirmed by ultrasonography) up to day 47. (For definitions of recurrence and extension of superficial-vein thrombosis, see the Supplementary Appendix, available at NEJM.org.) Secondary efficacy outcomes were the composite primary efficacy outcome up to day 77 and the following outcomes up to day 47 and day 77: each component of the primary efficacy outcome, the composite of symptomatic pulmonary embolism or deep-vein thrombosis, and surgery for superficial-vein thrombosis.

Analyses of safety outcomes were performed with data obtained until day 47 or until 4 days after the last injection of the study drug (whichever was longer), with data obtained until 4 days after the last injection of the study treatment (ontreatment analysis), and with data obtained until day 77 . The main safety outcome was major bleeding. Other safety outcomes were clinically relevant nonmajor, minor, and total (any) bleeding (definitions provided in the Supplementary Appendix) and arterial thromboembolic events. All other adverse events that occurred while the patient was receiving treatment were reported.

If a thromboembolic or bleeding complication occurred during the course of the study, management of the condition was left to the investigator's discretion. All symptomatic outcomes were reviewed by the central adjudication committee, whose members were unaware of the patients' group assignments. Patient safety was monitored by an independent data and safety monitoring committee.

\section{STATISTICAL ANALYSIS}

We estimated that with a sample of 1250 patients in each group, the study would have at least $98 \%$ power to detect a $50 \%$ reduction in the rate of the 
primary efficacy outcome, assuming an incidence of the primary efficacy outcome of $8.0 \%$ in the placebo group, $, 6,8,17$ at a two-sided $5 \%$ level of significance. As planned, the independent steering committee, whose members were unaware of the group assignments, monitored the overall event rate for the primary efficacy outcome. On November 5,2008 , on the basis of an observed rate of the primary efficacy outcome of $3.1 \%$, the committee decided to increase the sample to $3000 \mathrm{pa}$ tients in order to preserve at least $90 \%$ power to detect a $50 \%$ reduction in the rate of the primary efficacy outcome in the fondaparinux group.

Efficacy analyses were performed on data from the intention-to-treat population, which included all the patients who had undergone randomization. Patients for whom a primary efficacy assessment was lacking (i.e., those with no events and no information on their status with respect to efficacy at day $45 \pm 2$ ) were assumed not to have had any event. Safety analyses were performed on data from the as-treated population, which comprised all patients who had undergone randomization and who had received at least one dose of the study drug.

A two-sided Fisher's exact test at the 5\% significance level was performed for efficacy evaluations, and the resulting $\mathrm{P}$ values are reported. Absolute differences and relative risks, with 95\% confidence intervals, are also reported. Time-toevent outcomes estimated by means of the Kaplan-Meier method were compared with the use of the log-rank test. A prespecified sensitivity analysis was performed in which patients with missing data on the primary efficacy outcome were excluded. Zelen's exact test was used to verify the consistency of the treatment effect across 16 prespecified sets of subgroups and 1 set of subgroups that was defined post hoc. ${ }^{24}$

\section{RESULTS}

\section{STUDY POPULATIONS AND TREATMENTS}

Between March 2007 and May 2009, a total of 3002 patients were enrolled at 171 centers in 17 countries (see the Supplementary Appendix) 1502 in the fondaparinux group and 1500 in the placebo group. Of the 3002 patients who underwent randomization, 18 patients in the fondaparinux group (1.2\%) and 22 in the placebo group $(1.5 \%)$ did not have a primary efficacy assessment (Table 1 in the Supplementary Appendix). Overall, 1481 patients in the fondaparinux group (98.6\%) and 1467 in the placebo group (97.8\%) completed the follow-up visit at day $75 \pm 2$ (Table 2 in the Supplementary Appendix). Of the 3002 patients who underwent randomization, 4 patients in the fondaparinux group and 11 in the placebo group received no study drug (as a result of the patient's decision, in each case), and 1 patient who was randomly assigned to the placebo group received at least one dose of fondaparinux in error; thus, 1499 patients in the fondaparinux group $(99.8 \%)$ and 1488 in placebo group (99.2\%) were included in the safety analyses.

The demographic and clinical characteristics of the patients, the medications and interventions the patients received before their entry into the study (Table 1, and Table 3 in the Supplementary Appendix), the duration of treatment, and the adherence to treatment, as calculated with the use of a formula that was based on the number of syringes used and the number returned unused (Table 2), were well balanced between the two groups. In addition, the treatments other than the study drugs that patients received during the course of the study were well balanced between the two groups, with two exceptions: patients in the placebo group received anticoagulant drugs or oral nonsteroidal antiinflammatory drugs more frequently than did patients in the fondaparinux group (Table 2).

\section{EFFICACY OUTCOMES}

The primary efficacy outcome occurred in 13 of 1502 patients $(0.9 \%)$ in the fondaparinux group and 88 of 1500 patients (5.9\%) in the placebo group (relative risk with fondaparinux, 0.15 ; 95\% confidence interval [CI], 0.08 to 0.26 ; $\mathrm{P}<0.001$; number needed to treat, 20) (Table 3). This result was confirmed in the sensitivity analysis in which patients with a missing primary efficacy assessment were excluded (data not shown). The incidence of each component of the primary efficacy outcome was significantly reduced in the fondaparinux group as compared with the placebo group (including the incidence of pulmonary embolism [number needed to treat to prevent one pulmonary embolism was 300]), except for the incidence of death, which did not differ significantly between the two groups. The risk of the composite of deepvein thrombosis or pulmonary embolism was reduced by $85 \%$ with fondaparinux as compared with placebo $(0.2 \%$ [3 of 1502 patients] vs. $1.3 \%$ [20 of 1500 patients]; $\mathrm{P}<0.001$; number needed to treat, 88). All the efficacy results were main- 


\begin{tabular}{|c|c|c|c|}
\hline Characteristic & $\begin{array}{l}\text { Fondaparinux } \\
(\mathrm{N}=1502)\end{array}$ & $\begin{array}{l}\text { Placebo } \\
(\mathrm{N}=1500)\end{array}$ & P Value $\nrightarrow$ \\
\hline Age $-y r$ & $57.1 \pm 13.3$ & $56.9 \pm 13.6$ & 0.69 \\
\hline Female sex — no. (\%) & $974(64.8)$ & $944(62.9)$ & 0.29 \\
\hline \multicolumn{4}{|l|}{ Body-mass indext } \\
\hline Mean & $29.2 \pm 5.2$ & $29.0 \pm 5.4$ & 0.32 \\
\hline$\geq 30-$ no. (\%) & $574(38.2)$ & $536(35.7)$ & 0.16 \\
\hline \multicolumn{4}{|l|}{ Medical conditions - no. (\%) } \\
\hline Varicose veins & $1331(88.6)$ & $1329(88.6)$ & 1.00 \\
\hline Previous superficial-vein thrombosis & $178(11.9)$ & $178(11.9)$ & 1.00 \\
\hline Previous deep-vein thrombosis or pulmonary embolism & $105(7.0)$ & $104(6.9)$ & 1.00 \\
\hline Cardiovascular disease $\mathbb{Z}$ & $71(4.7)$ & $66(4.4)$ & 0.73 \\
\hline \multicolumn{4}{|l|}{ Heart failure or respiratory failure } \\
\hline Chronic & $71(4.7)$ & $88(5.9)$ & 0.17 \\
\hline Acuteq & $5(0.3)$ & $1(0.1)$ & 0.22 \\
\hline Known thrombophilia & $20(1.3)$ & $18(1.2)$ & 0.87 \\
\hline Autoimmune disease & $12(0.8)$ & $14(0.9)$ & 0.70 \\
\hline Acute infectious disease & $11(0.7)$ & $8(0.5)$ & 0.65 \\
\hline History of cancer & $32(2.1)$ & $29(1.9)$ & 0.80 \\
\hline Current hospitalization & $10(0.7)$ & $11(0.7)$ & 0.83 \\
\hline Trauma & $10(0.7)$ & $16(1.1)$ & 0.25 \\
\hline \multicolumn{4}{|l|}{ Treatment at inclusion — no. (\%) } \\
\hline Graduated compression stockings & $1131(75.3)$ & $1147(76.5)$ & 0.47 \\
\hline Analgesic agents & $391(26.0)$ & $401(26.7)$ & 0.68 \\
\hline Topical nonsteroidal antiinflammatory drugs & $598(39.8)$ & $608(40.5)$ & 0.71 \\
\hline Topical anticoagulant drugs & $57(3.8)$ & $50(3.3)$ & 0.55 \\
\hline Oral nonsteroidal antiinflammatory drugs or COX-2 inhibitors & $54(3.6)$ & $65(4.3)$ & 0.31 \\
\hline Oral or parenteral anticoagulant drugs & $67(4.5)$ & $58(3.9)$ & 0.46 \\
\hline Aspirin or other antiplatelet agents & $347(23.1)$ & $364(24.3)$ & 0.47 \\
\hline Glucocorticoids & $34(2.3)$ & $25(1.7)$ & 0.29 \\
\hline Oral contraceptive or hormone-replacement therapy & $43(2.9)$ & $40(2.7)$ & 0.82 \\
\hline \multicolumn{4}{|c|}{$\begin{array}{l}\text { Plus-minus values are means } \pm \text { SD. } \\
\text { The } P \text { values were calculated with the use of Student's t-test for continuous variables and Fisher's exact test for cate- } \\
\text { gorical variables. } \\
\text { The body-mass index is the weight in kilograms divided by the square of the height in meters. } \\
\text { Cardiovascular disease includes myocardial infarction, ischemic stroke, and peripheral arterial occlusive disorder. } \\
\text { Data are shown for patients in whom the condition was present at baseline or had occurred within the previous } \\
4 \text { weeks. }\end{array}$} \\
\hline
\end{tabular}

tained at day 77 (Fig. 1 and Table 3). The treatment effect was consistent across all the subgroups we examined (Fig. 2). Finally, more patients in the placebo group than in the fondaparinux group underwent surgery for superficial-vein thrombosis (Table 3), including ligation of the saphenofemoral junction, which by day 77 had been performed in 52 patients in the placebo group (3.5\%), as compared with 8 in the fondaparinux group $(0.5 \%)$.

\section{SAFETY OUTCOMES}

By day 47, major bleeding had occurred in one patient $(0.1 \%)$ in each group $(\mathrm{P}=1.00)$. The rates of clinically relevant nonmajor, minor, and total 


\begin{tabular}{|c|c|c|}
\hline Treatment & $\begin{array}{l}\text { Fondaparinux } \\
(\mathrm{N}=1502)\end{array}$ & $\begin{array}{l}\text { Placebo } \\
(\mathrm{N}=1500)\end{array}$ \\
\hline \multicolumn{3}{|l|}{ Study treatment } \\
\hline Receipt of at least one injection of study drug - no. (\%) & $1499(99.8)$ & $1488(99.2)$ \\
\hline Mean days of treatment & $43.6 \pm 7.3$ & $41.2 \pm 11.0$ \\
\hline \multicolumn{3}{|l|}{ Duration of treatment - no./total no. (\%) } \\
\hline$\leq 10$ days & $35 / 1499(2.3)$ & $95 / 1488(6.4)$ \\
\hline $11-30$ days & $26 / 1499(1.7)$ & $66 / 1488(4.4)$ \\
\hline $31-45$ days & $1161 / 1499(77.5)$ & $1091 / 1488(73.3)$ \\
\hline$>45$ days & $277 / 1499(18.5)$ & $236 / 1488(15.9)$ \\
\hline Self-administered treatment — no. (\%) & $1360 / 1499(90.7)$ & $1364 / 1488(91.7)$ \\
\hline \multicolumn{3}{|l|}{ Adherence to treatment } \\
\hline Patients who adhered - no. (\%) $\dagger$ & $1434(95.5)$ & $1329(88.6)$ \\
\hline Mean adherence $-\% \ddagger$ & $98.3 \pm 8.9$ & $98.4 \pm 8.7$ \\
\hline \multicolumn{3}{|l|}{ Other treatments } \\
\hline Graduated compression stockings - no. (\%) & $1247(83.0)$ & $1247(83.1)$ \\
\hline Analgesic agents - no. (\%) & $416(27.7)$ & $428(28.5)$ \\
\hline Topical nonsteroidal antiinflammatory drugs — no. (\%) & $623(41.5)$ & $627(41.8)$ \\
\hline Topical anticoagulant drugs — no. (\%) & $59(3.9)$ & $50(3.3)$ \\
\hline Oral nonsteroidal antiinflammatory drugs or COX-2 inhibitors — no. (\%) & $32(2.1)$ & $56(3.7)$ \\
\hline Oral or parenteral anticoagulant treatment - no. (\%)』 & $17(1.1)$ & $96(6.4)$ \\
\hline High (therapeutic) dose & $10(0.7)$ & $62(4.1)$ \\
\hline Intermediate dose & $1(0.1)$ & $6(0.4)$ \\
\hline Low (prophylactic) dose & $6(0.4)$ & $44(2.9)$ \\
\hline Unknown dose & $2(0.1)$ & $3(0.2)$ \\
\hline Aspirin or other antiplatelet agents - no. (\%) & $322(21.4)$ & $339(22.6)$ \\
\hline
\end{tabular}

* Plus-minus values are means \pm SD.

$\uparrow$ Patients were considered not to have adhered to treatment if they received less than $80 \%$ of the scheduled study drug (i.e., <36 injections) or if the last day of treatment was before day 40 . This included patients who discontinued treatment owing to an adverse event or a lack of efficacy.

$\ddagger$ Mean adherence was calculated with the use of the following formula: [(number of syringes dispensed-number of syringes returned-number of syringes lost or not returned and not used) $\div$ total number of days of treatment] $\times 100$.

$\int$ Patients could have received more than one anticoagulant treatment; different treatments might have been dispensed with the use of different dosage regimens (therapeutic, intermediate, or prophylactic).

bleeding and arterial thromboembolic complications did not differ significantly between the two groups (Table 4). Safety results were similar in on-treatment analyses and in analyses at day 77 (Table 4 in the Supplementary Appendix). There were no clinically relevant between-group differences in the incidence of any other adverse events (Table 5 and Table 6 in the Supplementary Appendix). The only serious adverse event that was reported in more than one patient in either study group was coronary artery disease, which was reported in two patients in the placebo group (0.1\%).
No episodes of thrombocytopenia were reported in the fondaparinux group.

\section{DISCUSSION}

In this study, we investigated the effect of anticoagulant therapy as compared with placebo on symptomatic outcomes in patients with isolated superficial-vein thrombosis. Treatment with fondaparinux at a dose of $2.5 \mathrm{mg}$ once daily for 45 days, as compared with placebo, resulted in an absolute risk reduction of 5 percentage points - which 


\begin{tabular}{|c|c|c|c|c|c|}
\hline \multirow[t]{2}{*}{ Efficacy Outcome } & $\begin{array}{l}\text { Fondaparinux } \\
(\mathrm{N}=1502)\end{array}$ & $\begin{array}{l}\text { Placebo } \\
(\mathrm{N}=1500)\end{array}$ & $\begin{array}{l}\text { Absolute Risk Reduction } \\
\text { with Fondaparinux }\end{array}$ & $\begin{array}{l}\text { Relative Risk with } \\
\text { Fondaparinux }\end{array}$ & P Value: \\
\hline & \multicolumn{2}{|c|}{ no. with event (\%) } & percentage points (95\% Cl) & $\%(95 \% \mathrm{Cl})$ & \\
\hline \multicolumn{6}{|l|}{ By Day 47} \\
\hline Primary composite outcome $\dagger$ & $13(0.9)$ & $88(5.9)$ & $-5.0(-6.3$ to -3.7$)$ & $0.15(0.08$ to 0.26$)$ & $<0.001$ \\
\hline Death & $2(0.1)$ & $1(0.1)$ & $0.1(-0.2$ to 0.3$)$ & 1.99 (0.18 to 21.87$)$ & 1.00 \\
\hline Pulmonary embolism $\int$ & 0 & $5(0.3)$ & $-0.3(-0.6$ to 0.0$)$ & Not calculated & 0.03 \\
\hline Deep-vein thrombosis 9 & $3(0.2)$ & $18(1.2)$ & $-1.0(-1.6$ to -0.4$)$ & $0.17(0.05$ to 0.56$)$ & $<0.001$ \\
\hline $\begin{array}{l}\text { Extension of superficial-vein thrombosis to } \\
\text { the saphenofemoral junction }\end{array}$ & $4(0.3)$ & $51(3.4)$ & $-3.1(-4.1$ to -2.2$)$ & $0.08(0.03$ to 0.22$)$ & $<0.001$ \\
\hline Recurrence of superficial-vein thrombosis & $5(0.3)$ & $24(1.6)$ & $-1.3(-2.0$ to -0.6$)$ & $0.21(0.08$ to 0.54$)$ & $<0.001$ \\
\hline Deep-vein thrombosis or pulmonary embolism & $3(0.2)$ & $20(1.3)$ & $-1.1(-1.8$ to -0.5$)$ & $0.15(0.05$ to 0.50$)$ & $<0.001$ \\
\hline Surgery for superficial-vein thrombosis & $11(0.7)$ & $57(3.8)$ & $-3.1(-4.1$ to -2.0$)$ & 0.19 (0.10 to 0.37$)$ & $<0.001$ \\
\hline \multicolumn{6}{|l|}{ By Day 77} \\
\hline Composite outcome $†$ & $18(1.2)$ & $94(6.3)$ & $-5.1(-6.4$ to -3.7$)$ & $0.19(0.12$ to 0.32$)$ & $<0.001$ \\
\hline Death & $2(0.1)$ & $1(0.1)$ & $0.1(-0.2$ to 0.3$)$ & 1.99 (0.18 to 21.87$)$ & 1.00 \\
\hline Pulmonary embolism $\int$ & 0 & $6(0.4)$ & $-0.4(-0.7$ to -0.1$)$ & Not calculated & 0.02 \\
\hline Deep-vein thrombosis & $4(0.3)$ & $19(1.3)$ & $-1.0(-1.6$ to -0.4$)$ & 0.21 (0.07 to 0.62$)$ & 0.001 \\
\hline $\begin{array}{l}\text { Extension of superficial-vein thrombosis to } \\
\text { the saphenofemoral junction }\end{array}$ & $5(0.3)$ & $54(3.6)$ & $-3.3(-4.3$ to -2.3$)$ & 0.09 (0.04 to 0.23$)$ & $<0.001$ \\
\hline Recurrence of superficial-vein thrombosis & $8(0.5)$ & $26(1.7)$ & $-1.2(-2.0$ to -0.4$)$ & 0.31 (0.14 to 0.68$)$ & 0.002 \\
\hline Deep-vein thrombosis or pulmonary embolism & $4(0.3)$ & $22(1.5)$ & $-1.2(-1.9$ to -0.5$)$ & $0.18(0.06$ to 0.53$)$ & $<0.001$ \\
\hline Surgery for superficial-vein thrombosis & $15(1.0)$ & $61(4.1)$ & $-3.1(-4.2$ to -1.9$)$ & $0.25(0.14$ to 0.43$)$ & $<0.001$ \\
\hline
\end{tabular}

* P values were calculated with the use of Fisher's exact test.

$\uparrow$ Some patients had more than one event.

$\checkmark$ There were two deaths from cancer in the fondaparinux group and one death from acute heart failure in the placebo group.

$\int$ No instance of pulmonary embolism was fatal.

I There were 11 cases of proximal deep-vein thrombosis: 1 in the fondaparinux group and 10 in the placebo group.

was equivalent to an $85 \%$ reduction in the risk of symptomatic thromboembolic complications or death - without increasing the incidence of bleeding. The number needed to treat to prevent one event of the primary efficacy outcome was 20 , whereas the number needed to treat to prevent deep-vein thromboembolism or a pulmonary embolism was 88 . The study was placebo-controlled, since no standard treatment has been established in this clinical setting. ${ }^{7,9}$ This design was considered to be ethical, since all the patients benefited from close clinical monitoring, with adequate diagnostic procedures performed in the event of new or persistent symptoms, and since an independent data and safety monitoring committee carefully oversaw the study outcomes.

The patients in our study are representative of those encountered in routine practice ${ }^{1,2,8}$ : almost all were outpatients, and there was a clear predominance of women and a substantial proportion of obese patients, most presenting with varicose veins and superficial-vein thrombosis involving the great saphenous vein. The rate of symptomatic thromboembolic complications in the placebo group at day 47 (5.9\%; 95\% CI, 4.7 to 7.2$)$ was in the low range of the expected rate of thromboembolic events, possibly because very-high-risk patients (e.g., those with active cancer or a recent history of venous thromboembolism and those in whom the thrombus was located within $3 \mathrm{~cm}$ of the saphenofemoral junction) were not enrolled in this placebo-controlled trial. However, this rate and the corresponding rate at day 77 (6.3\%; $95 \%$ CI, 5.1 to 7.6) are consistent with that observed at 3 months in a prospective observational study in which a similar composite outcome was evaluated 


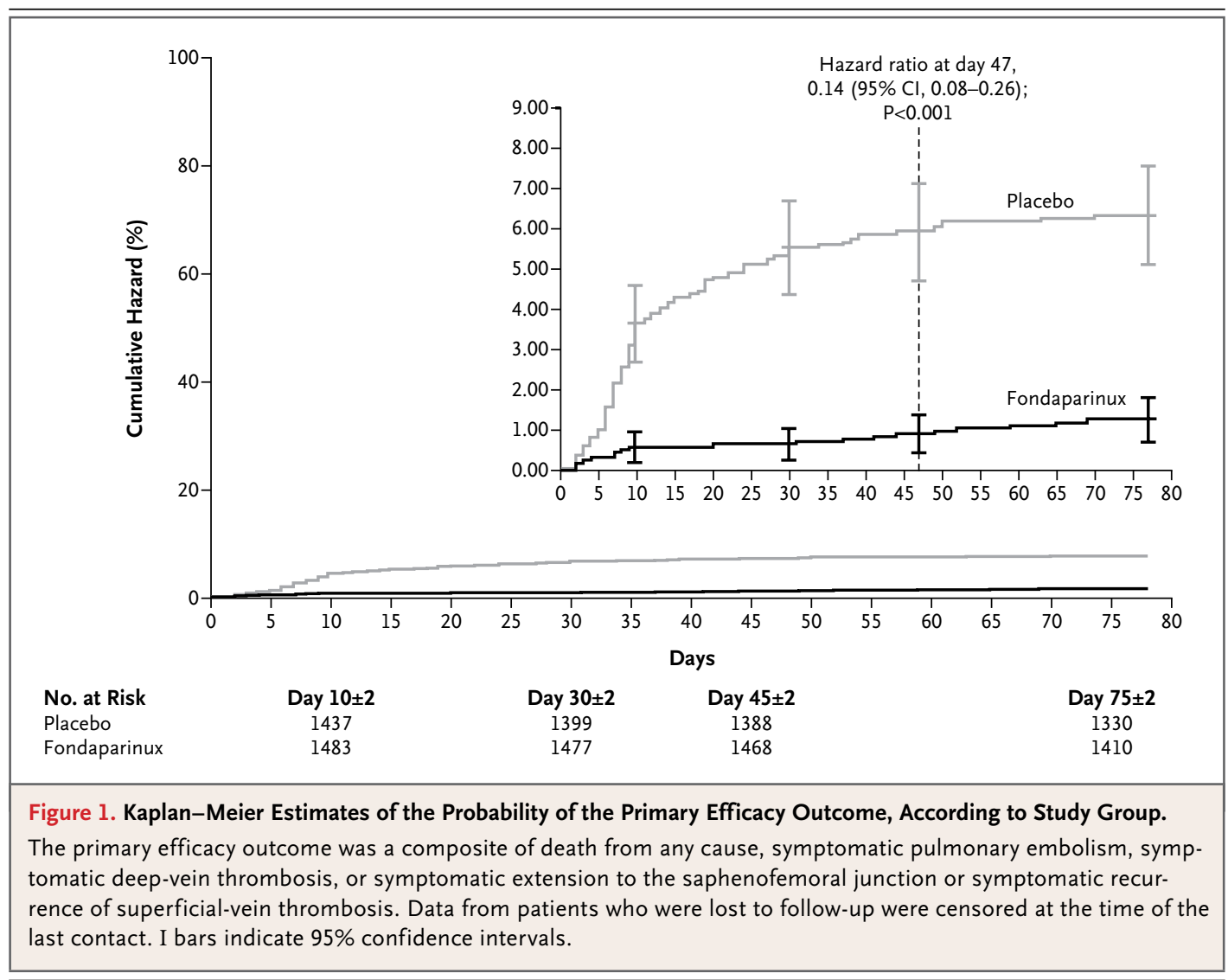

(8.3\%; 95\% CI, 6.0 to 10.6 ), ${ }^{8}$ confirming that superficial-vein thrombosis is not a benign disease.

The relative reduction of $85 \%$ in the risk of symptomatic events that we observed with $2.5 \mathrm{mg}$ of fondaparinux daily as compared with placebo is consistent with the reduction in the risk of venous thromboembolic complications that has been observed in studies evaluating anticoagulant agents as compared with placebo or no therapy for prophylaxis ${ }^{25-28}$ or treatment ${ }^{29}$ of venous thromboembolism. This benefit was evident within the first days after treatment was initiated (Fig. 1), supporting the adequacy of the prophylactic dose of $2.5 \mathrm{mg}$ of fondaparinux and in accord with the substantial efficacy data already available with respect to a dose of $2.5 \mathrm{mg}$ of fondaparinux in various clinical settings. ${ }^{20-23}$ We chose a 45-day duration of treatment with the specific objective of avoiding the "catch-up" phenomenon observed with shorter (up to 30-day) courses of low-molecular-weight heparin..$^{6,17}$ This objective was met, since the efficacy of fondaparinux efficacy was maintained through day 77.

As compared with placebo, fondaparinux also significantly reduced, by the same magnitude, the risk of each thromboembolic component of the primary efficacy outcome and was associated with a clinically important and statistically significant reduction of $85 \%$ in the risk of the composite outcome of symptomatic deep-vein thrombosis or pulmonary embolism at day 47 . The number needed to treat to prevent one episode of pulmonary embolism with fondaparinux as compared with placebo in the patients with superficial-vein thrombosis in our study (300) is similar to the number needed to treat with low-molecular-weight heparin as compared with placebo or no treatment in trials of thromboprophylaxis in acutely ill medical patients (345). ${ }^{28}$ Fondaparinux also reduced the risk of symptomatic recurrence of superficial-vein thrombosis and, more important, its extension to the saphenofemoral junction a finding that is clinically relevant because such extension is considered to increase the risk of deep-vein thrombosis and pulmonary embolism, thereby prompting escalation of therapy (e.g., to full-dose anticoagulation or surgery). ${ }^{1,2,6,8,10,11,14}$ In our study, fondaparinux reduced by $81 \%$ the rate 


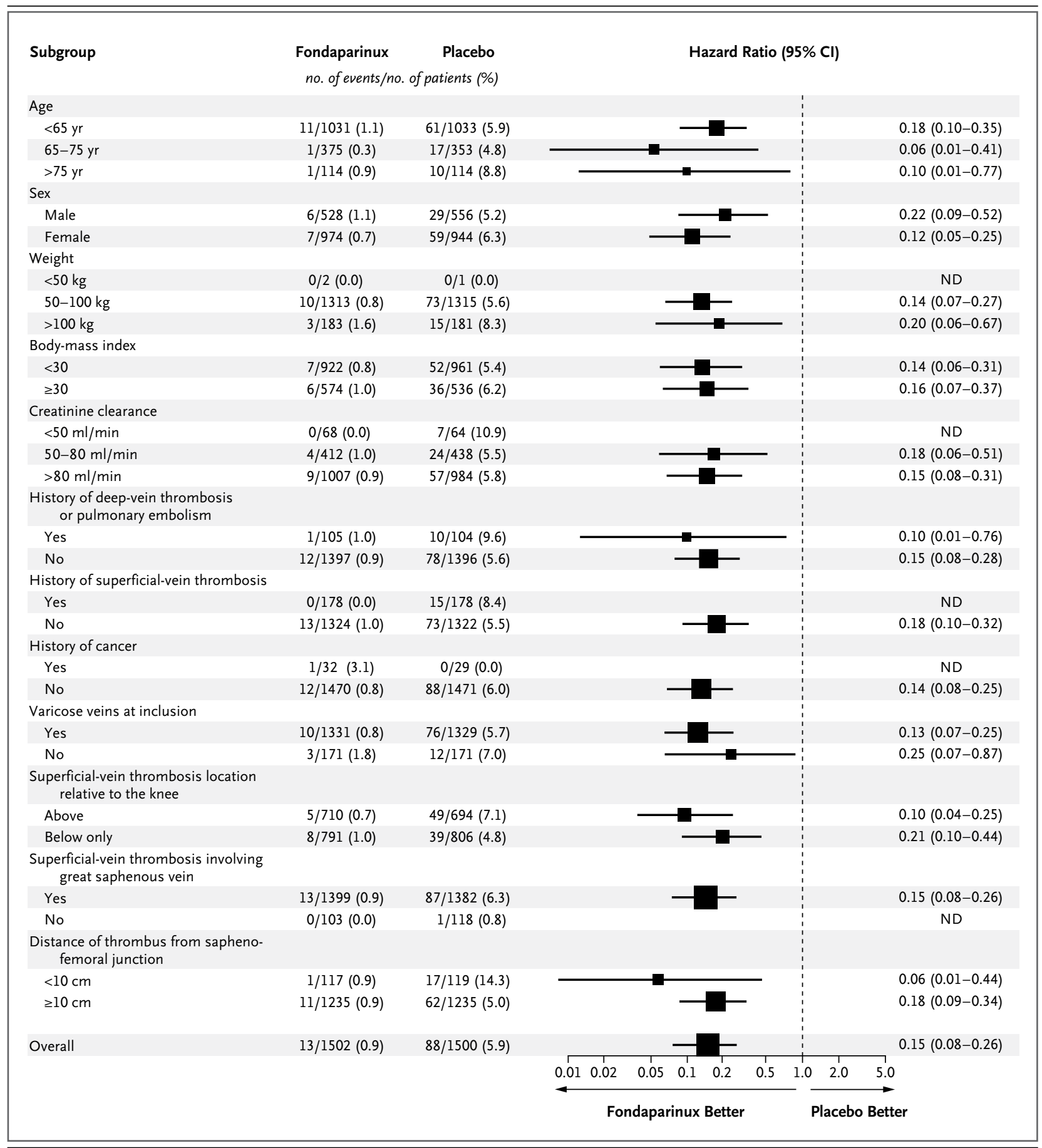

of surgery, primarily ligation of the saphenofemoral junction, for superficial-vein thrombosis a prespecified secondary outcome. In addition, more patients in the placebo group than in the fondaparinux group required therapeutic doses of anticoagulant therapy.

A potential limitation of our study is the difficulty in applying the data to clinical practice, because a complete ultrasonographic examination was performed in every patient with a suspected superficial-vein thrombosis - first, to confirm the condition, and second, to rule out the presence of deep-vein thrombosis. However, performing a complete ultrasonographic examination may help physicians avoid treating patients who do not have thrombosis and allow the appropriate 
Figure 2 (facing page). Rates of the Primary Efficacy Outcome at Day 47 in Prespecified Subgroups.

The primary efficacy outcome was a composite of death from any cause, symptomatic pulmonary embolism, symptomatic deep-vein thrombosis, or symptomatic extension to the saphenofemoral junction or symptomatic recurrence of superficial-vein thrombosis. The size of each square is in proportion to the number of patients in the comparison. The analysis of subgroups according to the distance of thrombus from the saphenofemoral junction included only subjects who had a thrombosis involving the great saphenous vein. No adjustment for multiple comparisons was made, since subgroup analyses were performed for exploratory purposes only. None of the $P$ values for interaction were less than 0.10 (data not shown). Results for 12 of the 16 prespecified subgroups are presented; the treatment effect was also consistent within each of the 4 other prespecified subgroups (defined according to country and status with respect to receipt of graduated compression stockings, use of nonsteroidal antiinflammatory drugs, and use of aspirin or other antiplatelet agents at baseline), as well as the subgroup defined post hoc (defined according to whether the index superficial-vein thrombosis was in a varicose vein on ultrasonographic examination). The body-mass in dex is the weight in kilograms divided by the square of the height in meters. ND denotes not determined.

care of patients who present with concomitant deep-vein thrombosis. ${ }^{8}$ Our results were obtained without the use of repeat systematic compression ultrasonography - in contrast to clinical practice in certain countries. ${ }^{8}$ The 45 -day regimen of subcutaneous injections could also be questioned from a practical standpoint. However, the feasibility of such treatment was confirmed by the high degree of patient adherence; more than $90 \%$ of patients injected themselves with the study drug. The effect of the 45-day fondaparinux regimen on the quality of life was not formally assessed in our study. However, the significantly reduced risk of symptomatic complications and of recourse to surgery or therapeutic doses of anticoagulant agents that we observed with fondaparinux therapy is likely to be associated with an improved quality of life. Finally, the cost-effectiveness of a 45-day regimen of fondaparinux remains to be evaluated, taking into account the clinical events that may be prevented with treatment and factors that potentially vary across countries, such as the direct cost of fondaparinux and the clinical management (including diagnostic and therapeutic procedures) that is currently proposed in routine practice when fondaparinux is not used.
Table 4. Safety Outcomes up to Day 47.

\begin{tabular}{|c|c|c|}
\hline Safety Outcome & $\begin{array}{l}\text { Fondaparinux } \\
(\mathrm{N}=1499)\end{array}$ & $\begin{array}{c}\text { Placebo } \\
(\mathrm{N}=1488)\end{array}$ \\
\hline & \multicolumn{2}{|c|}{ no. with event (\%) } \\
\hline \multicolumn{3}{|l|}{ Bleeding } \\
\hline Major* & $1(0.1)$ & $1(0.1)$ \\
\hline Fatal & 0 & 0 \\
\hline Symptomatic in a critical organ $†$ & $1(0.1)$ & 0 \\
\hline $\begin{array}{l}\text { Causing } 2 \mathrm{~g} / \mathrm{dl} \text { fall in hemoglobin or neces- } \\
\text { sitating transfusion of } \geq 2 \text { units of } \\
\text { packed red cells or whole blood }+\end{array}$ & 0 & $1(0.1)$ \\
\hline Clinically relevant nonmajor & $5(0.3)$ & $8(0.5)$ \\
\hline Minor & $9(0.6)$ & $6(0.4)$ \\
\hline Any & $15(1.0)$ & $14(0.9)$ \\
\hline Arterial thromboembolic complication $\mathbb{S}$ & 0 & $3(0.2)$ \\
\hline Any adverse event & $195(13.0)$ & $199(13.4)$ \\
\hline Drug-related & $56(3.7)$ & $49(3.3)$ \\
\hline Nonfatal serious & $10(0.7)$ & $16(1.1)$ \\
\hline Leading to discontinuation of study treatment & $18(1.2)$ & $29(1.9)$ \\
\hline Leading to withdrawal from study & $2(0.1)$ & $1(0.1)$ \\
\hline
\end{tabular}

$* P=1.00$ with the use of Fisher's exact test.

$\uparrow$ One patient in the fondaparinux group had retinal bleeding that resolved after the discontinuation of study treatment; there were no functional consequences that affected vision.

$¥$ One patient in the placebo group had epistaxis that necessitated medical intervention but that resolved without further consequences.

$\int$ There were two cases of acute coronary syndrome and one of ischemic stroke - all in the placebo group.

In conclusion, patients with isolated, symptomatic superficial-vein thrombosis in the legs are at substantial risk for symptomatic thromboembolic complications. Fondaparinux administered at a dose of $2.5 \mathrm{mg}$ once daily for 45 days is effective and widely applicable for the treatment of such patients.

Supported by a grant from GlaxoSmithKline.

Dr. Decousus reports receiving research grant support from Bayer, Boehringer Ingelheim, Bristol-Myers Squibb, and GlaxoSmithKline and fees for board memberships from Bayer, Daiichi Sankyo, GlaxoSmithKline, and Sanofi-Aventis; Dr. Prandoni, receiving research grant support and consulting fees from GlaxoSmithKline; Dr. Mismetti, receiving research grant support from GlaxoSmithKline and fees for board memberships or symposia from Bayer, Boehringer Ingelheim, GlaxoSmithKline, and Sanofi-Aventis; Dr. Bauersachs, receiving consulting fees or honoraria from Sanofi-Aventis, Pfizer, and GlaxoSmithKline; Dr. Brenner, serving on advisory boards for GlaxoSmithKline, Sanofi-Aventis, Pfizer, and Bayer Pharmaceuticals and receiving lecture fees from GlaxoSmithKline, Sanofi-Aventis, Bayer Pharmaceuticals, and Boehringer Ingelheim and grant support from Sanofi-Aventis; Dr. Laporte, receiving research grant support from Bayer and Sanofi-Aventis and fees for board memberships or consulting from Bayer, Boehringer Ingelheim, GlaxoSmith- 
Kline, and Sanofi-Aventis; Dr. Middeldorp, receiving consulting fees from GlaxoSmithKline; Dr. Sokurenko, receiving research grant support from GlaxoSmithKline and lecture fees from GlaxoSmithKline; and Dr. Leizorovicz, receiving research grant support from Bristol-Myers Squibb and fees for board member- ships from Bayer Pharmaceuticals, Boehringer Ingelheim, GlaxoSmithKline, and Sanofi-Aventis. No other potential conflict of interest relevant to this article was reported.

Disclosure forms provided by the authors are available with the full text of this article at NEJM.org.
REFERENCES

1. Decousus $\mathrm{H}$, Epinat $\mathrm{M}$, Guillot $\mathrm{K}$, Quenet S, Boissier C, Tardy B. Superficial vein thrombosis: risk factors, diagnosis, and treatment. Curr Opin Pulm Med 2003; 9:393-7.

2. Marchiori A, Mosena L, Prandoni P. Superficial vein thrombosis: risk factors, diagnosis and treatment. Semin Thromb Hemost 2006;32:737-43.

3. Heit JA, Silverstein MD, Mohr DN, Petterson TM, O'Fallon WM, Melton LJ III. Risk factors for deep vein thrombosis and pulmonary embolism: a populationbased case-control study. Arch Intern Med 2000;160:809-15.

4. Di Minno G, Mannucci PM, Tufano A, et al. The First Ambulatory Screening on Thromboembolism: a multicentre, crosssectional, observational study on risk factors for venous thromboembolism. J Thromb Haemost 2005;3:1459-66.

5. van Weert $H$, Dolan $G$, Wichers I, de Vries C, ter Riet G, Buller H. Spontaneous superficial venous thrombophlebitis: does it increase risk for thromboembolism? A historic follow-up study in primary care. J Fam Pract 2006;55:52-7.

6. The Superficial Thrombophlebitis Treated by Enoxaparin Study Group. A randomized double-blind comparison of lowmolecular-weight heparin, a nonsteroidal anti-inflammatory agent, and placebo in the treatment of superficial-vein thrombosis. Arch Intern Med 2003;163:1657-63. 7. Di Nisio M, Wichers IM, Middeldorp $S$. Treatment for superficial thrombophlebitis of the leg. Cochrane Database Syst Rev 2007;2:CD004982.

8. Decousus H, Quere I, Presle E, et al. Superficial vein thrombosis and venous thromboembolism: a large, prospective epidemiological study. Ann Intern Med 2010;152:218-24.

9. Kearon C, Kahn SR, Agnelli G, Goldhaber S, Raskob GE, Comerota AJ. Antithrombotic therapy for venous thromboembolic disease: American College of Chest Physicians Evidence-Based Clinical Practice Guidelines (8th Edition). Chest 2008;133:Suppl:454S-545S.

10. De Maeseneer MG. Superficial thrombophlebitis of the lower limb: practical recommendations for diagnosis and treatment. Acta Chir Belg 2005;105:145-7.
11. Jeanneret C, Baldi T, Jenelten R. La thrombophlébite superficielle: une vue d'ensemble. Forum Med Suisse 2006;6: 190-5.

12. Cesarone MR, Belcaro G, Agus G, et al. Management of superficial vein thrombosis and thrombophlebitis: status and expert opinion document. Angiology 2007; 58:Suppl 1:7S-14S. [Erratum, Angiology 2008;59:519.]

13. Wichers IM, Haighton M, Buller HR, Middeldorp S. A retrospective analysis of patients treated for superficial vein thrombosis. Neth J Med 2008;66:423-7.

14. Agence Française de Sécurité Sanitaire des Produits de Santé (AFSSAPS). Recommandations de bonne pratique: prévention et traitement de la maladie thromboembolique veineuse en médecine. November 2009. (Accessed August 30, 2010, at http://www .afssaps.fr/Afssaps-media/Publications/ Recommandations-de-bonne-pratique.)

15. Belcaro G, Nicolaides AN, Errichi BM, et al. Superficial thrombophlebitis of the legs: a randomized, controlled follow-up study. Angiology 1999;50:523-9.

16. Lozano FS, Almazan A. Low-molecular-weight heparin versus saphenofemoral disconnection for the treatment of aboveknee greater saphenous thrombophlebitis: a prospective study. Vasc Endovascular Surg 2003;37:415-20.

17. Prandoni P, Tormene D, Pseavento $\mathrm{R}$. High vs. low doses of low-molecularweight heparin for the treatment of superficial vein thrombosis of the legs: a double-blind, randomized trial. J Thromb Haemost 2005;3:1152-7.

18. Marchiori A, Verlato F, Sabbion P, et al. High versus low doses of unfractionated heparin for the treatment of superficial thrombophlebitis of the leg: a prospective, controlled, randomized study. Haematologica 2002;87:523-7.

19. Titon JP, Auger D, Grange P, et al. Traitement curatif des thromboses veineuses superficielles par nadroparine calcique: recherche posologique et comparaison à un anti-inflammatoire non stéroïdien. Ann Cardiol Angeiol (Paris) 1994;43:160-6.

20. Turpie AGG, Bauer KA, Eriksson BI, Lassen MR. Fondaparinux versus enoxaparin for the prevention of venous thromboembolism in major orthopedic surgery: a meta-analysis of 4 randomized doubleblind studies. Arch Intern Med 2002; 162:1833-40.

21. Agnelli G, Bergqvist D, Cohen AT, Gallus AS, Gent M. Randomized clinical trial of postoperative fondaparinux versus perioperative dalteparin for prevention of venous thromboembolism in high-risk abdominal surgery. Br J Surg 2005;92:1212-20.

22. Cohen AT, Davidson BL, Gallus AS, et al. Efficacy and safety of fondaparinux for the prevention of venous thromboembolism in older acute medical patients: randomised placebo controlled trial. BMJ 2006; 332:325-9.

23. The Fifth Organization to Assess Strategies in Acute Ischemic Syndromes Investigators. Comparison of fondaparinux and enoxaparin in acute coronary syndromes. N Engl J Med 2006;354:1464-76.

24. Wang R, Lagakos SW, Ware JH, Hunter DJ, Drazen JM. Statistics in medicine reporting of subgroup analyses in clinical trials. N Engl J Med 2007;357:2189-94.

25. Mismetti P, Laporte S, Darmon JY, Buchmüller A, Decousus H. Meta-analysis of low molecular weight heparin in the prevention of venous thromboembolism in general surgery. Br J Surg 2001;88:913-30. 26. Eikelboom JW, Quinlan DJ, Douketis JD. Extended-duration prophylaxis against venous thromboembolism after total hip or knee replacement: a meta-analysis of the randomised trials. Lancet 2001;358:915.

27. Eriksson BI, Lassen MR. Duration of prophylaxis against venous thromboembolism with fondaparinux after hip fracture surgery: a multicenter, randomized, placebo-controlled, double-blind study. Arch Intern Med 2003;163:1337-42.

28. Dentali F, Douketis JD, Gianni M, Lim W, Crowther MA. Meta-analysis: anticoagulant prophylaxis to prevent symptomatic venous thromboembolism in hospitalized medical patients. Ann Intern Med 2007;146:278-88.

29. Brandjes DP, Heijboer H, Büller HR, de Rijk M, Jagt H, ten Cate JW. Acenocoumarol and heparin compared with acenocoumarol alone in the initial treatment of proximal-vein thrombosis. N Engl J Med 1992;327:1485-9.

Copyright (c) 2010 Massachusetts Medical Society. 